Rev. Bras. Saúde Prod. Anim., Salvador, v.13, n.2, p.344-359 abr./jun., 2012 http://www.rbspa.ufba.br ISSN 15199940

\title{
Taxa de deposição de tecidos corporais de novilhas Nelore e suas cruzas com Angus e Simental ${ }^{1}$
}

\author{
Deposition patterns of body tissues of Nellore and crossbreed with Angus and \\ simmental heifers
}

\author{
SOUZA, Evaristo Jorge Oliveira de ${ }^{2^{*}}$; VALADARES FILHO, Sebastião de Campos ${ }^{3}$; \\ GUIM, Adriana ${ }^{4}$; VALADARES, Rilene Ferreira Diniz ${ }^{3}$; PAULINO, Pedro Veiga \\ Rodrigues $^{3}$; FERREIRA, Marcelo de Andrade ${ }^{4}$; TORRES, Thaysa Rodrigues ${ }^{4}$; \\ LAGE, Josiane Fonseca ${ }^{5}$
}

\author{
${ }^{1}$ Financiado pela Fundação de Amparo à Pesquisa de Minas Gerais (FAPEMIG) e Conselho Nacional de \\ Pesquisa $(\mathrm{CNPq})$. \\ ${ }^{2}$ Universidade Federal Rural de Pernambuco, Serra Talhada, Pernambuco, Brasil. \\ ${ }^{3}$ Universidade Federal de Viçosa, Departamento de Zootecnia, Viçosa, Minas Gerais, Brasil. \\ ${ }^{4}$ Universidade Federal Rural de Pernambuco, Departamento de Zootecnia, Recife, Pernambuco, Brasil. \\ ${ }^{5}$ Universidade Estadual Paulista, Departamento de Zootecnia, Jaboticabal, São Paulo, Brasil. \\ *Endereço para correspondência: evaristo@uast.ufrpe.br
}

\section{RESUMO}

Objetivou-se avaliar a taxa de deposição de tecidos corporais de novilhas Nelore e suas cruzas com Angus e Simental. Foram utilizadas 57 novilhas de três grupos genéticos, das quais 19 eram do grupo Nelore, 19 Angus e 19 Simental, destas 12 (4 de cada grupo genético) foram abatidas no início do experimento (grupo referência) para estimativa da composição da carcaça dos demais animais. Outras 36 novilhas (12 animais de cada grupo genético) foram distribuídas em seis tratamentos, em esquema fatorial $3 \times 2$, de modo a constituir três grupos genéticos (Nelore, Angus e Simental) e dois níveis de oferta de concentrado (30 e 50\% da matéria seca da ração em concentrado), com seis repetições por tratamento. As nove novilhas restantes foram utilizadas em um experimento paralelo (quadrado latino) para determinação da digestibilidade das rações experimentais. Ao final do experimento, todos os animais foram abatidos e a composição corporal determinada. O percentual de gordura subcutânea foi maior para as novilhas Angus. Os constituintes químicos do peso de corpo vazio e do ganho de peso de corpo vazio não sofreram efeito dos grupos genéticos. Constatou-se que o cruzamento entre fêmeas Nelore com animais Angus, bem como o nível de concentrado melhoram o padrão de deposição dos tecidos corporais.

Palavras-chave: composição do ganho, tecido adiposo, tecido muscular

\section{SUMMARY}

The objective of this work was to evaluate deposition pattems of body tissues of Nellore and crossbreed with Angus and Simmental heifers. Fifty seven heifers (19 Nellore, 19 Angus and 19 Simmental) were used, being 12 heifers (four in each genetic group) slaughtered before the beginning of the experiment as the baseline group. Thirty six (twelve in each genetic group) were ad libitun fed with 30 (six in each group) and $50 \%$ (six in each group) of dry matter diet in concentrate. The animals were in a completely randomized design, $3 \times 2$ factorial (tree genetic group and two diet), with six replicates per treatment. Nine remaining animals were used for a digestibility trial. At the end of the experiment all these animals were slaughtered and its corporal composition determined. The percentage of subcutaneous fat was greater for Angus heifers. Chemical constituents of empty body weight and empty body gain there did not suffer effects of genetic group. The crossing between Nellore and Angus, as well as the level of concentrate improve carcass characteristics and pattern of deposition of body tissues.

Keywords: adipose tissue, gain composition, muscle tissue 


\section{INTRODUÇ̃̃̃O}

A raça Nelore é a mais criada no Brasil, em virtude de suas características de adaptação às condições edafo-climáticas dos trópicos. Entretanto, os índices de produtividade do rebanho nacional são menores quando comparados a de rebanhos de outros países. A utilização de raças europeias, que apresentam maior potencial de crescimento, pode ser uma alternativa para se aumentar a taxa de desfrute do rebanho nacional. Nesse sentido, Rocha Júnior et al. (2010) relataram que os cruzamentos entre raças zebuínas e europeias têm proporcionado à pecuária de corte nacional os benefícios do vigor híbrido, com incremento da produtividade do rebanho. Ocorre que a falta de adaptabilidade desses animais às condições edafo-climáticas de grande parte do Brasil dificulta sua utilização.

Diversas estratégias podem ser utilizadas para melhorar os índices produtivos do rebanho nacional, como a terminação de fêmeas em confinamento e o uso de cruzamentos entre animais taurinos e zebuínos (PEROTTO et al., 2001a; EUCLIDES FILHO et al., 2003). Bianchini et al. (2008) relataram que, as características da carne bovina apresentam herdabilidade bastante variável. Assim, é fundamental avaliar as interações entre os diferentes grupos genéticos.

Vaz \& Rastle (2003) defendem que cruzamentos entre taurinos e zebuínos têm se mostrado vantajosos, pois otimizam o uso de efeitos não aditivos (heterose) e efeitos aditivos (complementariedade de raças), principalmente, quanto aos aspectos relacionados à carcaça. Entre os benefícios que os cruzamentos proporcionam à pecuária bovina de corte, o aumento do peso e a melhoria da qualidade das carcaças estão entre os que podem ser alcançados mais rapidamente (MORALES et al., 2002; CAMARGO et al., 2008).

Novilhas, quando confinadas, ainda na fase final de crescimento, podem apresentar ganho de peso muito eficiente. Fêmeas atingem graus de terminação aceitáveis mais facilmente que os machos, pois, de acordo com Marcondes et al. (2009) estas tendem a depositar gordura mais precocemente, seguidas por machos não castrados e machos inteiros.

Os animais cruzados apresentaram superioridade no que concerne ao ganho de peso e ao rendimento de carcaça. No entanto, existe enorme carência de dados relacionados à taxa de deposição de tecidos corporais de fêmeas Nelore ou provenientes de cruzamentos com Angus ou Simental.

Diante disso, objetivou-se avaliar a taxa de deposição de tecidos corporais de novilhas Nelore e suas cruzas com Angus e Simental.

\section{MATERIAL E MÉTODOS}

Foram utilizadas 57 novilhas de três grupos genéticos, 19 Nelore (NE) com média de $247,80 \pm 16,71 \mathrm{~kg} ; 19 \mathrm{~F}_{1}$ Nelore $x$ Angus (NA), com média de $292,94 \pm 17,85 \mathrm{~kg}$ e $19 \quad F_{1}$ Nelore $\mathrm{x}$ Simental (NS) de $258,64 \pm 34,06 \mathrm{~kg}$, com idade média de 18 meses. Doze animais pertencentes ao grupo referência, utilizado para estimativa da composição inicial da carcaça e do corpo vazio dos animais, disponíveis no confinamento (quatro de cada grupo genético), foram abatidos ao início do experimento. Outras 36 novilhas (12 animais de cada grupo genético) foram distribuídas em delineamento inteiramente casualizado, em esquema fatorial $2 \times 3$, assim descrito, dois níveis de concentrado (30 
ou $50 \%$ da matéria seca da ração em concentrado) e três grupos genéticos (NE, NA e NS).

Os nove animais restantes foram utilizados em um experimento paralelo (quadrado latino) para determinação da digestibilidade das rações experimentais.

As dietas experimentais foram compostas por silagem de milho, fubá de milho, farelo de soja, ureia pecuária, bicarbonato de sódio, óxido de magnésio, mistura mineral e cloreto de sódio (Tabelas 1 e 2). Os animais foram alojados em baias individuais, providas de comedouro e bebedouro de concreto, com área total de $30 \mathrm{~m}^{2}$, com $8 \mathrm{~m}^{2}$ de área coberta, no confinamento experimental do Departamento de Zootecnia da Universidade Federal de Viçosa, em Viçosa, MG. Os alimentos foram fornecidos, na forma de ração total, duas vezes ao dia ( 8 e 16h) e as quantidades oferecidas foram ajustadas, diariamente, de forma a permitir sobras em torno de 5\%. A água potável estava permanentemente à disposição dos animais. $\mathrm{O}$ experimento teve duração de 142 dias, aproveitados do seguinte modo: 30 dias de adaptação dos animais às condições experimentais e 112 dias (quatro períodos de 28 dias cada) para coleta dos dados e amostras.

Para determinação do ganho de peso, as novilhas foram pesadas a cada 28 dias. Foram coletadas amostras dos ingredientes que faziam parte do concentrado, da silagem de milho e das sobras de cada animal. As amostras foram agrupadas, de forma proporcional, em cada período de 28 dias, a constituírem-se em amostras compostas, as quais foram pré-secas em estufa de ventilação forçada a $65^{\circ} \mathrm{C}$ e moídas em moinho, com peneira de malha de $1 \mathrm{~mm}$, para posterior determinações laboratoriais.

Transcorrido o período experimental, iniciaram-se os abates. Seis animais eram abatidos por dia (um de cada grupo genético e nível de concentrado), com um intervalo de um dia para dissecação das carcaças entre cada abate. A utilização de um período experimental com duração fixa teve o objetivo de determinar diferenças na composição corporal de fêmeas Nelore, $\mathrm{F}_{1}$ Angus $\mathrm{x}$ Nelore ou $\mathrm{F}_{1}$ Simental $\mathrm{x}$ Nelore.

Tabela 1. Composição química dos principais ingredientes das dietas

\begin{tabular}{lccc}
\hline \multirow{2}{*}{ Nutrientes } & \multicolumn{3}{c}{ Alimentos } \\
\cline { 2 - 4 } & $\begin{array}{c}\text { Silagem de } \\
\text { Milho }\end{array}$ & $\begin{array}{c}\text { Fubá de } \\
\text { Milho }\end{array}$ & $\begin{array}{c}\text { Farelo de } \\
\text { Soja }\end{array}$ \\
\hline Matéria seca (MS),\% & 28,27 & 87,93 & 87,36 \\
Matéria orgânica (\%MS) & 94,93 & 98,84 & 93,93 \\
Proteína bruta (\%MS) & 6,96 & 8,27 & 51,95 \\
Extrato etéreo (\%MS) & 2,52 & 4,15 & 3,71 \\
Fibra em detergente neutro-FDN (\%MS) & 50,82 & 10,83 & 15,18 \\
FDN corrigida para cinzas e proteína (\%MS) & 46,08 & 10,06 & 9,47 \\
Carboidratos não fibrosos (\%MS) & 34,63 & 75,59 & 23,08 \\
\hline
\end{tabular}


Rev. Bras. Saúde Prod. Anim., Salvador, v.13, n.2, p.344-359 abr./jun., 2012 http://www.rbspa.ufba.br ISSN 15199940

Tabela 2. Proporção dos ingredientes e composição percentual e química das dietas experimentais

\begin{tabular}{|c|c|c|}
\hline \multirow{2}{*}{ Ingredientes (\% na MS) } & \multicolumn{2}{|c|}{ Níveis de Concentrado } \\
\hline & $30 \%$ & $50 \%$ \\
\hline Silagem de milho & 69,10 & 50,00 \\
\hline Fubá de milho & 23,37 & 38,95 \\
\hline Farelo de soja & 5,49 & 9,16 \\
\hline Ureia+Sulfato de amônio & 1,14 & 0,40 \\
\hline Cloreto de sódio & 0,30 & 0,50 \\
\hline Mistura mineral $^{1}$ & 0,30 & 0,50 \\
\hline Óxido de magnésio & 0,10 & 0,17 \\
\hline Bicarbonato de sódio & 0,20 & 0,33 \\
\hline Nutrientes & \multicolumn{2}{|c|}{ Composição Nutricional } \\
\hline Matéria seca (MS),\% & 38,11 & 45,35 \\
\hline Matéria orgânica (\%MS) & 94,99 & 94,96 \\
\hline Extrato etéreo (\%MS) & 2,92 & 3,21 \\
\hline Proteína bruta (\%MS) & 12,46 & 12,42 \\
\hline Energia metabolizável (Mcal/kgMS) ${ }^{2}$ & 2,35 & 2,67 \\
\hline Fibra em detergente neutro-FDN (\%MS) & 38,48 & 30,84 \\
\hline FDN corrigida para cinzas e proteína (\%MS) & 34,85 & 27,89 \\
\hline Carboidratos não fibrosos $(\% \mathrm{MS})$ & 46,50 & 52,04 \\
\hline
\end{tabular}

${ }^{1}$ Mistura mineral: $\mathrm{Ca}-24,0 \%$; P - 17,4\%; Co - 100,0ppm; $\mathrm{Cu}-1.250,0 \mathrm{ppm} ; \mathrm{Fe}-1.795,0 \mathrm{ppm} ; \mathrm{Mn}-$ 2.000,0ppm; Se - 15,0ppm; Zn - 5.270,0ppm; I - 90,0ppm.

${ }^{2}$ Estimado a partir do consumo de nutrientes digestíveis totais

Antes do abate, os animais foram submetidos a jejum de sólidos, de 16 horas. O abate foi realizado via insensibilização e secção da jugular para sangramento total, seguido de lavagem do aparelho gastrintestinal (rúmen, retículo, omaso, abomaso e intestinos delgado e grosso). Os pesos do coração, pulmões, fígado, baço, rins, gordura interna, carne industrial, mesentério, cauda e aparas (esôfago, traqueia e aparelho reprodutor), juntamente com os do trato gastrintestinal lavado, foram somados aos das demais partes do corpo (carcaça, cabeça, couro, pés e sangue) para determinação do peso de corpo vazio (PCVZ).

A carcaça de cada animal foi dividida em duas meia-carcaças, as quais foram pesadas e, em seguida, resfriadas em câmara fria $\mathrm{a}-5^{\circ} \mathrm{C}$, durante 18 horas.
Transcorrido o resfriamento, as carcaças foram novamente pesadas e tiveram suas medidas de espessura de gordura mensurada na altura da $12^{\mathrm{a}}$ costela e seu comprimento medido. A meia-carcaça direita foi dissecada em tecidos adiposo, muscular e ósseo. O tecido adiposo, por sua vez, foi subdividido em tecido adiposo subcutâneo e intermuscular, pesados separadamente. Todos os tecidos (subcutâneo + intermuscular) foram pesados e moídos, posteriormente, foi obtida, de forma proporcional ao peso de cada carcaça, uma amostra composta de músculo e gordura da carcaça.

Os ossos da carcaça foram subdivididos em três classes: ossos longos (representados pelos ossos dos membros anteriores e posteriores e da pelve), costelas e vértebras. Os ossos, dentro de 
cada classificação, foram pesados, serrados e amostrados separadamente. Depois de serrados, obteve-se, de forma proporcional ao peso total dos ossos, uma amostra composta. A partir do procedimento descrito acima, obteve-se a composição física da carcaça.

As amostras dos ossos e a composta de músculos mais gordura foram armazenadas a $-20^{\circ} \mathrm{C}$. Em seguida, as amostras foram submetidas a um prédesengorduramento (MSPD) por extração com éter de petróleo, no aparelho Soxhlet por $6 \mathrm{~h}$. Em seguida, as amostras foram moídas em moinho de bola, para determinações de matéria seca (MS), cinzas, nitrogênio total e extrato etéreo (EE). As determinações de MS, cinzas, EE e do nitrogênio total das amostras dos constituintes corporais foram realizadas de acordo com recomendações de Silva \& Queiroz (2002), já o teor de proteína bruta (PB) obtido pelo produto entre $\mathrm{O}$ nitrogênio total e o fator 5,88 , conforme sugerido por Baldwin (1995).

A partir dos teores de MS, PB, EE e cinzas, encontrados nas amostras de todos os constituintes da carcaça e do corpo vazio, conforme descritos previamente, obtiveram-se os teores de água, EE, PB e MM na carcaça e no corpo vazio dos animais. A partir da composição inicial, estimada pelos animais do grupo referência, determinou-se a composição do ganho de peso dos animais, ao longo do experimento.

As amostras da silagem de milho e dos ingredientes dos concentrados (fubá de milho, farelo de soja, ureia e minerais) foram analisadas quanto aos seus teores de MS, MM, compostos nitrogenados, $\mathrm{EE}$, por meio das metodologias descritas por Silva \& Queiroz (2002). A determinação da fibra em detergente neutro (FDN) foi efetuada pela técnica de fiber bags (Ankom ${ }^{\circledR}$ ), segundo a metodologia descrita por Silva \&
Queiroz (2002), com modificação do saco utilizado $(5,0 \times 5,0 \mathrm{~cm}$, porosidade de $100 \mu \mathrm{m})$, confeccionado com tecido não tecido - TNT $\left(100 \mathrm{~g} / \mathrm{m}^{2}\right)$. Em virtude da presença de ureia na constituição dos concentrados e nas dietas, o teor de carboidratos não fibrosos foi calculado como proposto por Hall (2000): $\mathrm{CNF}=$ $100 \%-[(\% \mathrm{~PB}-\% \mathrm{~PB}$ Ureia $+\%$ Ureia $)+$ $\%$ FDN $+\%$ EE $+\%$ Cinzas $)]$.

Para estimativa das digestibilidades aparentes dos nutrientes, foram realizadas coleta total de fezes, por três dias consecutivos, nos animais do quadrado latino. Para estimativa dos nutrientes digestíveis totais (NDT), foi utilizada a equação descrita por Weiss (1999), na qual NDT = PBD + EED*2,25 + CNFD + FDNDcp, onde PBD, EED, CNFD e FDNcp significam, respectivamente, proteína bruta digestível, extrato etéreo digestível, carboidratos não fibrosos digestíveis e fibra em detergente neutro (corrigida para cinzas e proteína) digestível. A conversão de energia digestível (ED) em EM foi executada de acordo com o NRC (2000), segundo a equação $\mathrm{EM}=$ $0,82 * \mathrm{ED}$ (considere-se que um quilo de NDT equivale a 4,409Mcal de ED).

Os dados foram avaliados por intermédio de análises da variância, através do programa Statistical Analysis Sistems (SAS, 2000), com o seguinte modelo: $\mathrm{Y}_{\mathrm{ijk}}=\mu+\mathrm{A}_{\mathrm{i}}+\mathrm{B}_{\mathrm{j}}+(\mathrm{AB})_{\mathrm{ij}}+$ $e_{\mathrm{ijk}}$, onde: $\mathrm{Y}_{\mathrm{ijk}}$ é o valor da característica para repetição " $\mathrm{k}$ " que recebeu o nível "i" do fator " $A$ " e o nível de " $j$ " do fator "B", $\mu$ é a média geral, $A_{i}$ é o efeito do nível "i" do fator " $A$ ", $B_{i}$ é o efeito do nível " $\mathrm{j}$ " do fator "B", $(A B)_{\mathrm{ij}}$ é o efeito da interação dos fatores " $\mathrm{A}$ " e " $\mathrm{B}$ ", $e_{\mathrm{ijk}} \mathrm{e}$ $o$ erro da unidade experimental " $k$ " que recebeu o nível " $i$ " do fator " $A$ " e o nível " $\mathrm{j}$ " do fator "B". Adotou-se o nível de $10 \%$ de probabilidade para as comparações entre as médias, realizadas a partir do teste de Tukey. 


\section{RESULTADOS E DISCUSSÃO}

Não houve interação $(\mathrm{P}>0,10)$ entre o nível de oferta de concentrado e o grupo genético para nenhuma das variáveis avaliadas. Dessa forma, os efeitos de grupo genético e nível de oferta de concentrado foram analisados e discutidos separadamente.

A dieta com o maior nível de concentrado proporcionou aumento de $24,12 \%$ na quantidade de gordura na carcaça $(\mathrm{P}<0,10)$, como pode ser observado na Tabela 3 , resultado que pode ser atribuído ao maior aporte de energia dessa dieta $(21,50 \mathrm{Mcal}$ de EM/dia). A quantidade total e percentual do tecido muscular não foi influenciada pelo nível de concentrado ofertado $(\mathrm{P}>0,10)$.

A composição física da carcaça foi afetada pelo grupo genético $(\mathrm{P}<0,10)$, cujo grupo Angus apresentou maior quantidade de tecido adiposo e muscular depositado na carcaça $(\mathrm{P}<0,10)$, quando comparado aos demais grupos genéticos (Nelore e Simental). Isso pode ser explicado pelo maior peso de carcaça observado nessas novilhas $(247,0 ; 206,7$ e $201,9 \mathrm{~kg}$, respectivamente, para Angus, Simental e Nelore). Contudo, quando esses valores foram expressos em percentual ao peso da carcaça, apenas o percentual de gordura apresentou diferenças significativas entre os grupos genéticos $(\mathrm{P}<0,10)$. Vale lembrar que expressar as características de carcaças, percentualmente, não é a forma mais indicada para indicar os valores de heterose, e sim, a composição da carcaça em peso total de músculo, gordura e osso. Nessa direção, Perotto et al. (2001b) mostraram não haver diferenças significativas nos percentuais de tecido muscular, tecido adiposo e tecido ósseo entre Nelore, Nelore $\mathrm{x}$
Guzerá, Nelore x Red Angus, Nelore x Marchigiana e Nelore x Simental.

Com exceção dos teores de extrato etéreo $(\mathrm{P}<0,10)$ e cinzas $(\mathrm{P}<0,10)$, que sofreram influência dos teores de gordura e ossos respectivamente (Tabela 3), a composição química da carcaça não sofreu interferência do nível de oferta de concentrado $(\mathrm{P}>0,10)$.

$\mathrm{O}$ maior nível energético das rações com $50 \%$ de concentrado $(2,35 \mathrm{Mcal}$ de $\mathrm{EM} / \mathrm{kg}$ de MS para $30 \%$ de concentrado e 2,67Mcal de EM/kg de MS para $50 \%$ de concentrado na ração) proporcionou incremento na deposição de extrato etéreo e consequentemente redução dos teores de cinzas na carcaça. Maiores deposições de gordura reduzem as deposições de minerais, pois a concentração desses elementos inorgânicos no tecido adiposo é menor que nos músculos e ossos (PAULINO et al., 2009).

Com exceção do tecido ósseo, o maior nível de concentrado na dieta proporcionou maior taxa de deposição dos tecidos na carcaça (Tabela 4). Dessa forma, fica evidente que, quando os grãos apresentarem preços vantajosos, dietas com níveis de concentrado mais elevado tornam-se alternativas viáveis do ponto de vista econômico e biológico para os confinadores, já que proporcionam maiores taxas de deposição dos tecidos. Além disso, o maior nível de concentrado (50\%) proporcionou maior eficiência de utilização da energia metabolizável consumida $(\mathrm{P}<0,10)$ para depósito de extrato etéreo na carcaça (Tabela 4).

$\mathrm{O}$ grupo genético teve efeito significativo $(\mathrm{P}<0,10)$ sobre as taxas de deposição dos tecidos (Tabela 4). As novilhas NA apresentaram as maiores taxas de deposição de gordura $(\mathrm{P}<0,10)$. 
Tabela 3. Composição física e química da carcaça de fêmeas Nelore, $F_{1}$ Nelore x Angus e $F_{1}$ Nelore x Simental, alimentadas com dois níveis de concentrado (30 e 50\%)

\begin{tabular}{|c|c|c|c|c|c|c|c|c|c|}
\hline \multirow[b]{2}{*}{ Variáveis } & \multicolumn{2}{|c|}{$\begin{array}{l}\text { Nível Concentrado } \\
\text { (NC) }\end{array}$} & \multicolumn{3}{|c|}{$\begin{array}{l}\text { Grupo Genético } \\
\text { (GG) }\end{array}$} & \multirow[b]{2}{*}{$\begin{array}{l}\text { CV } \\
(\%)\end{array}$} & \multicolumn{3}{|c|}{ Valor P } \\
\hline & $30 \%$ & $50 \%$ & Nelore & $\begin{array}{c}\text { Nelore } \\
\text { x } \\
\text { Angus }\end{array}$ & $\begin{array}{c}\text { Nelore } \\
\mathrm{x} \\
\text { Simental } \\
\end{array}$ & & $\mathrm{NC}$ & GG & $\begin{array}{c}\mathrm{NC} \\
\mathrm{x} \\
\mathrm{GG} \\
\end{array}$ \\
\hline \multicolumn{10}{|c|}{ Composição Física } \\
\hline Gordura total (kg) & $24,63^{b}$ & $30,57^{\mathrm{a}}$ & $28,18^{\mathrm{b}}$ & $31,62^{\mathrm{a}}$ & $23,01^{\mathrm{c}}$ & 30,89 & 0,062 & $<, 0001$ & 0,88 \\
\hline Gordura $(\%)$ & $23,50^{\mathrm{b}}$ & $26,31^{\mathrm{a}}$ & $26,47^{\mathrm{a}}$ & $26,09^{\mathrm{a}}$ & $22,16^{\mathrm{b}}$ & 17,78 & 0,085 & 0,073 & 0,74 \\
\hline Músculo (kg) & 63,67 & 67,26 & $60,77^{\mathrm{b}}$ & $72,02^{\mathrm{a}}$ & $63,60^{\mathrm{b}}$ & 10,25 & 0,14 & 0,0013 & 0,73 \\
\hline Músculo (\%) & 61,09 & 59,67 & 59,18 & 59,64 & 62,33 & 6,05 & 0,28 & 0,13 & 0,70 \\
\hline Músculo+Gordura (kg) & $88,52^{\mathrm{b}}$ & $95,25^{\mathrm{a}}$ & $85,43^{\mathrm{b}}$ & $103,97^{\mathrm{a}}$ & $86,26^{\mathrm{b}}$ & 11,36 & 0,08 & 0,0003 & 0,55 \\
\hline Músculo+Gordura (\%) & $84,59^{b}$ & $85,98^{\mathrm{a}}$ & 85,65 & 85,72 & 84,49 & 2,53 & 0,079 & 0,37 & 0,38 \\
\hline Osso total $(\mathrm{kg})$ & 16,06 & 15,72 & 14,70 & 17,23 & 15,74 & 17,17 & 0,73 & 0,10 & 0,46 \\
\hline Osso $(\%)$ & $15,41^{\mathrm{a}}$ & $14,02^{\mathrm{b}}$ & 14,35 & 14,28 & 15,51 & 14,76 & 0,079 & 0,37 & 0,38 \\
\hline Músculo:Osso ${ }^{1}$ & 3,97 & 4,08 & $4,14^{\mathrm{a}}$ & $3,90^{\mathrm{b}}$ & $4,03^{\mathrm{ab}}$ & 5,25 & 0,18 & 0,04 & 0,85 \\
\hline Músculo:gordura $^{1}$ & 2,06 & 1,89 & $1,88^{\mathrm{b}}$ & $1,82^{b}$ & $2,23^{\mathrm{a}}$ & 18,59 & 0,20 & 0,034 & 0,77 \\
\hline Músculo+Gordura:Osso ${ }^{1}$ & 5,52 & 5,76 & 5,83 & 5,64 & 5,47 & 7,74 & 0,14 & 0,19 & 0,64 \\
\hline \multicolumn{10}{|c|}{ Composição Química (\%) } \\
\hline Proteína & 16,10 & 16,16 & $15,81^{\mathrm{ab}}$ & $15,62^{b}$ & $16,96^{\mathrm{a}}$ & 8,60 & 0,90 & 0,078 & 0,43 \\
\hline Extrato etéreo & $21,63^{\mathrm{b}}$ & $23,80^{\mathrm{a}}$ & 23,54 & 23,37 & 21,23 & 13,98 & 0,066 & 0,21 & 0,43 \\
\hline Cinzas & $5,27^{\mathrm{a}}$ & $4,51^{\mathrm{b}}$ & 4,89 & 4,74 & 5,04 & 17,36 & 0,016 & 0,71 & 0,95 \\
\hline Água & 57,00 & 55,54 & 55,76 & 56,27 & 56,77 & 5,72 & 0,21 & 0,78 & 0,45 \\
\hline
\end{tabular}


Tabela 4. Taxas de deposição dos tecidos e dos constituintes químicos do ganho da carcaça de fêmeas Nelore, $F_{1}$ Nelore $x_{\text {Angus e }} F_{1}$ Nelore x Simental, alimentadas com dois níveis de concentrado (30 e 50\%)

\begin{tabular}{|c|c|c|c|c|c|c|c|c|c|}
\hline \multirow[b]{2}{*}{ Valores } & \multicolumn{2}{|c|}{$\begin{array}{l}\text { Nível de Concentrado } \\
\text { (NC) }\end{array}$} & \multicolumn{3}{|c|}{$\begin{array}{l}\text { Grupo Genético } \\
\text { (GG) }\end{array}$} & \multirow[b]{2}{*}{ CV $(\%)$} & \multicolumn{3}{|c|}{ Valor P } \\
\hline & $30 \%$ & $50 \%$ & Nelore & $\begin{array}{c}\text { Nelore } \\
\mathrm{x} \\
\text { Angus } \\
\end{array}$ & $\begin{array}{c}\text { Nelore } \\
\mathrm{x} \\
\text { Simental } \\
\end{array}$ & & $\mathrm{NC}$ & GG & $\begin{array}{c}\mathrm{NC} \\
\mathrm{X} \\
\mathrm{GG} \\
\end{array}$ \\
\hline \multicolumn{10}{|c|}{ Taxa de deposição dos tecidos } \\
\hline Espessura Gordura subcutânea (CZ/dia) & 0,034 & 0,039 & $0,036^{\mathrm{ab}}$ & $0,051^{\mathrm{a}}$ & $0,025^{\mathrm{b}}$ & 41,51 & 0,34 & 0,0041 & 0,49 \\
\hline Gordura subcutânea (g/dia) & $63,2^{\mathrm{b}}$ & $78,6^{\mathrm{a}}$ & $65,4^{\mathrm{b}}$ & $91,1^{\mathrm{a}}$ & $56,1^{\mathrm{c}}$ & 24,59 & 0,025 & 0,0005 & 0,06 \\
\hline Gordura Intermuscular (g/dia) & $74,9^{\mathrm{b}}$ & $99,8^{\mathrm{a}}$ & $74,3^{b}$ & $103,9^{\mathrm{a}}$ & $83,6^{\mathrm{ab}}$ & 33,16 & 0,028 & 0,0074 & 0,37 \\
\hline Gordura Total & $137,9^{\mathrm{b}}$ & $178,4^{\mathrm{a}}$ & $139,7^{b}$ & $195,1^{\mathrm{a}}$ & $139,7^{\mathrm{b}}$ & 26,82 & 0,016 & 0,0088 & 0,16 \\
\hline Músculo & $136,1^{\mathrm{b}}$ & $183,3^{\mathrm{a}}$ & 148,2 & 186,9 & 143,9 & 33,02 & 0,024 & 0,15 & 0,65 \\
\hline Osso & 19,9 & 24,8 & 25,9 & 26,1 & 25,2 & 57,94 & 0,32 & 0,18 & 0,87 \\
\hline \multicolumn{10}{|c|}{ Taxa de deposição dos constituintes químicos, g/dia } \\
\hline Proteína & $98,54^{\mathrm{b}}$ & $131,06^{\mathrm{a}}$ & 95,14 & 121,50 & 127,76 & 35,06 & 0,039 & 0,19 & 0,75 \\
\hline Extrato etéreo & $234,6^{\mathrm{b}}$ & $307,1^{\mathrm{a}}$ & $223,5^{\mathrm{b}}$ & $335,6^{\mathrm{a}}$ & $253,4^{\mathrm{b}}$ & 34,12 & 0,038 & 0,023 & 0,23 \\
\hline Cinzas & 22,4 & 18,9 & 21,6 & 23,3 & 17,0 & 66,09 & 0,49 & 0,59 & 0,44 \\
\hline Água & 303,1 & 322,4 & $290,3^{\mathrm{ab}}$ & $388,6^{\mathrm{a}}$ & $259,3^{\mathrm{b}}$ & 40,08 & 0,67 & 0,059 & 0,70 \\
\hline \multicolumn{10}{|c|}{ Eficiência de deposição dos constituintes químicos, $\mathrm{kg} / \mathrm{Mcal}$ de $\mathrm{EM}^{1}$ consumida } \\
\hline Constituintes químicos totais $^{2}$ & 3,84 & 4,47 & $3,64^{\mathrm{b}}$ & $5,09^{\mathrm{a}}$ & $3,74^{\mathrm{b}}$ & 30,36 & 0,18 & 0,0198 & 0,49 \\
\hline Proteína & 0,60 & 0,71 & 0,51 & 0,76 & 0,69 & 44,43 & 0,32 & 0,14 & 0,81 \\
\hline Extrato etéreo & $1,37^{b}$ & $1,80^{\mathrm{a}}$ & $1,31^{\mathrm{b}}$ & $1,98^{\mathrm{a}}$ & $1,47^{\mathrm{b}}$ & 34,14 & 0,033 & 0,020 & 0,24 \\
\hline
\end{tabular}
diferentes, diferem entre si $(P<0,10)$ pelo teste de Tukey. 
Diferenças na maturidade explicam esse comportamento, em que as NA já estavam em fase de acabamento e as outras não, o que reflete na maior deposição de gordura. De acordo com Euclides Filho et al. (2001), os animais $\mathrm{F}_{1}$ Nelore $\mathrm{x}$ Angus necessitam ser mantidos por um período menor de alimentação, pois atingem o ponto de terminação mais rapidamente, quando comparados aos Nelore e Nelore $\mathrm{x}$ Simental.

Para todas as taxas de deposição dos tecidos e constituintes químicos na carcaça, o cruzamento NS não superou o NE comportamento semelhante foi encontrado por Perotto et al. (2001b), que, ao trabalharem com vários cruzamentos entre Nelore e animais de origem europeia, não encontraram superioridade do cruzamento NS em relação aos NE, para peso e composição da carcaça, principalmente no que se refere ao tecido adiposo. Esse comportamento deve ser decorrente da menor precocidade dos animais da raça Simental, principalmente no que respeita ao tecido adiposo.

Perotto et al. (2001b) relataram que a raça Simental apresenta uma musculatura moderada, com tamanho à maturidade grande e, dessa forma, animais com maior tamanho adulto demoram mais tempo para atingir o mesmo grau de maturidade (acabamento) que animais de menor tamanho adulto. Dessa forma, fica evidente que o cruzamento entre animais de origem europeia e zebu pode ser uma ferramenta importante para se aumentar os índices de produtividade da pecuária de corte no Brasil. De acordo com Malhado et al. (2009), a variabilidade de recursos genéticos existente, tanto em zebuínos como em taurinos, pode atender às diferentes demandas dos sistemas de produção. No entanto, deve-se ter cuidado com a maturidade tardia dos animais utilizados para tais cruzamentos. Segundo
Fernandes et al. (2004), animais menos precoces apresentam menor taxa de deposição de gordura, e torna-se pertinente ressaltar que a ausência ou quantidade insuficiente de gordura na carcaça pode influenciar negativamente os atributos de qualidade da carne.

Com relação à taxa de deposição dos componentes químicos da carcaça (g/dia), só a proteína e o extrato etéreo foram afetados pela oferta de concentrado $(\mathrm{P}<0,10)$. $\mathrm{O}$ maior nível de concentrado apresentou maior taxa de deposição desses constituintes químicos.

Apesar do tecido adiposo e muscular diferir do conteúdo de extrato etéreo e proteína, respectivamente (SAINZ \& HASTING, 2000), seria normal que o maior nível de concentrado, que apresentaram maior nível de tecido adiposo e muscular, apresentasse também maior teor de extrato etéreo e proteína bruta. Os coeficientes de correlação entre tecido adiposo e extrato etéreo, e entre tecido muscular e proteína bruta, foram significativos $(r=0,89$ e $r=0,81 ; P<0,10$, respectivamente, para extrato etéreo e proteína bruta), o que demonstra uma forte associação entre essas variáveis.

Esse mesmo comportamento foi verificado para taxa de deposição do extrato etéreo em relação ao grupo genético $(\mathrm{P}<0,10)$, ou seja, os animais que apresentaram mais tecido adiposo (Angus) também apresentaram maior taxa de deposição desse constituinte químico. Esse resultado é reflexo da maior eficiência de deposição dos constituintes químicos totais e extrato etéreo na carcaça $(\mathrm{P}<0,10)$ dos Angus (Tabela 4).

A composição de ganho na carcaça não foi influenciada $(\mathrm{P}>0,10)$ pelo nível de concentrado e grupo genético (Tabela 5), dado que reflete o fato dos animais terem a mesma idade cronológica e estarem na mesma fase de crescimento. 
A composição do ganho de peso e a eficiência de utilização dos nutrientes (principalmente energia e proteína) diferem de acordo com a fase de crescimento em que o animal se encontra, pois, até o animal atingir a maturidade, o tecido muscular é o principal constituinte do ganho de peso, e após a puberdade, o tecido adiposo passa a ser o principal constituinte do ganho.

Tabela 5. Composição do ganho de carcaça de fêmeas Nelore, $F_{1}$ Nelore $x$ Angus e $F_{1}$ Nelore x Simental, alimentadas com dois níveis de concentrado (30 e 50\%)

\begin{tabular}{|c|c|c|c|c|c|c|c|c|c|}
\hline \multirow[b]{2}{*}{ Variáveis } & \multicolumn{2}{|c|}{$\begin{array}{l}\text { Nível concentrado } \\
\text { (NC) }\end{array}$} & \multicolumn{3}{|c|}{$\begin{array}{c}\text { Grupo Genético } \\
\text { (GG) }\end{array}$} & \multirow[b]{2}{*}{$\begin{array}{l}\text { CV } \\
(\%)\end{array}$} & \multicolumn{3}{|c|}{ Valor P } \\
\hline & $30 \%$ & $50 \%$ & Nelore & $\begin{array}{l}\text { Nelore } \\
\mathrm{x} \\
\text { Angus }\end{array}$ & $\begin{array}{c}\text { Nelore } \\
x \\
\text { Simental }\end{array}$ & & $\mathrm{NC}$ & GG & $\begin{array}{c}\mathrm{NC} \\
\mathrm{x} \\
\mathrm{GG}\end{array}$ \\
\hline \multicolumn{10}{|c|}{ Composição tecidual de ganho, \% } \\
\hline Gordura Subcutânea & 22,15 & 21,23 & 23,32 & 22,81 & 18,94 & 23,89 & 0,62 & 0,14 & 0,81 \\
\hline $\begin{array}{l}\text { Gordura } \\
\text { Intermuscular }\end{array}$ & 26,33 & 26,69 & 26,12 & 25,82 & 27,58 & 28,68 & 0,90 & 0,85 & 0,22 \\
\hline Gordura Total & 48,49 & 47,91 & 49,45 & 48,64 & 46,52 & 23,87 & 0,89 & 0,84 & 0,45 \\
\hline Músculo & 45,52 & 47,60 & 46,38 & 47,83 & 45,47 & 19,29 & 0,52 & 0,83 & 0,65 \\
\hline Osso & 5,99 & 6,79 & $5,15^{\mathrm{b}}$ & $5,99^{\mathrm{b}}$ & $8,02^{\mathrm{a}}$ & 43,15 & 0,43 & 0,08 & 0,60 \\
\hline \multicolumn{10}{|c|}{ Composição química de ganho, $\%$} \\
\hline Proteína & 15,65 & 15,61 & 13,36 & 14,62 & 17,26 & 26,21 & 0,86 & 0,10 & 0,52 \\
\hline Extrato Etéreo & 36,86 & 39,92 & 36,29 & 38,61 & 40,38 & 26,04 & 0,34 & 0,65 & 0,97 \\
\hline Cinzas & 3,84 & 2,76 & 3,86 & 2,66 & 3,11 & 65,22 & 0,26 & 0,58 & 0,61 \\
\hline Água & 43,65 & 41,70 & 46,27 & 43,35 & 38,56 & 19,99 & 0,58 & 0,12 & 0,80 \\
\hline
\end{tabular}

Médias, na mesma linha, dentro do nível de concentrado ou grupo genético, seguidas por letras diferentes, diferem entre si $(\mathrm{P}<0,10)$ pelo teste de Tukey.

À medida que a ingestão de energia aumenta acima da mantença, a taxa de síntese de proteína passa a ser o primeiro limitante, e o excesso de energia é depositado como gordura. Como as dietas experimentais apresentaram densidade energética diferentes $(\mathrm{P}<0,10), 2,51 \mathrm{e}$ $2,58 \mathrm{Mcal} / \mathrm{kg}$ de $\mathrm{MS}$, respectivamente, para 30 e $50 \%$ de concentrado na ração, é coerente que quase todas as formas de depósito de gordura no corpo do animal fossem afetadas pelo nível de concentrado ofertado, como pode ser visto na Tabela 6.
As novilhas NA tiveram uma maior participação do tecido adiposo no corpo vazio do que as novilhas Nelore e Simental $(\mathrm{P}<0,10)$, o que revela a maior precocidade desse grupo genético (Tabela 6). Observa-se que, independente do nível de oferta de concentrado e do grupo genético, o tecido adiposo intermuscular foi o local em que foi depositado a maior parte da gordura, seguido pelo mesentérico, pelo subcutâneo e por último, o perirrenal. 
Rev. Bras. Saúde Prod. Anim., Salvador, v.13, n.2, p.344-359 abr./jun., 2012 http://www.rbspa.ufba.br ISSN 15199940

Tabela 6. Principais depósitos de gordura corporal de fêmeas Nelore, $F_{1}$ Nelore x Angus e $F_{1}$ Nelore $x$ Simental, alimentadas com dois níveis de concentrado (30 e 50\%)

\begin{tabular}{|c|c|c|c|c|c|c|c|c|c|}
\hline \multirow[b]{2}{*}{ Variáveis } & \multicolumn{2}{|c|}{$\begin{array}{c}\text { Nível de } \\
\text { concentrado (NC) }\end{array}$} & \multicolumn{3}{|c|}{$\begin{array}{l}\text { Grupo genético } \\
\text { (GG) }\end{array}$} & \multirow{2}{*}{$\begin{array}{l}\text { CV } \\
(\%)\end{array}$} & \multicolumn{3}{|c|}{ Valor P } \\
\hline & $30 \%$ & $50 \%$ & Nelore & $\begin{array}{c}\text { Nelore } \\
\mathrm{x} \\
\text { Angus }\end{array}$ & $\begin{array}{c}\text { Nelore } \\
x \\
\text { Simental } \\
\end{array}$ & & $\mathrm{NC}$ & GG & $\begin{array}{c}\mathrm{NC} \\
\mathrm{x} \\
\mathrm{GG} \\
\end{array}$ \\
\hline \multicolumn{10}{|c|}{$\%$ da gordura total } \\
\hline $\begin{array}{l}\text { Gordura } \\
\text { subcutânea }\end{array}$ & $19,35^{\mathrm{b}}$ & $22,07^{\mathrm{a}}$ & $19,91^{\mathrm{b}}$ & $26,13^{\mathrm{a}}$ & $16,10^{\mathrm{b}}$ & 21,02 & 0,093 & $<, 001$ & 0,156 \\
\hline $\begin{array}{l}\text { Gordura } \\
\text { intermuscular }\end{array}$ & $33,1^{\mathrm{b}}$ & $37,84^{\mathrm{a}}$ & $32,68^{b}$ & $41,16^{\mathrm{a}}$ & $32,57^{\mathrm{b}}$ & 19,49 & 0,064 & 0,009 & 0,489 \\
\hline $\begin{array}{l}\text { Gordura } \\
\text { perirrenal }\end{array}$ & 14,80 & 15,83 & $13,32^{\mathrm{b}}$ & $18,68^{\mathrm{a}}$ & $13,95^{\mathrm{b}}$ & 24,43 & 0,446 & 0,004 & 0,828 \\
\hline $\begin{array}{l}\text { Gordura } \\
\text { mesentérica }\end{array}$ & $29,94^{\mathrm{b}}$ & $34,64^{\mathrm{a}}$ & $31,05^{\mathrm{b}}$ & $38,62^{\mathrm{a}}$ & $27,20^{\mathrm{b}}$ & 17,48 & 0,027 & 0,003 & 0,201 \\
\hline \multicolumn{10}{|c|}{$\%$ do peso de corpo vazio } \\
\hline $\begin{array}{l}\text { Gordura } \\
\text { subcutânea }\end{array}$ & $2,60^{\mathrm{b}}$ & $2,96^{\mathrm{a}}$ & $2,67^{\mathrm{b}}$ & $3,51^{\mathrm{a}}$ & $2,16^{\mathrm{b}}$ & 21,00 & 0,093 & $<, 001$ & 0,155 \\
\hline $\begin{array}{l}\text { Gordura } \\
\text { intermuscular }\end{array}$ & $4,44^{\mathrm{b}}$ & $5,08^{\mathrm{a}}$ & $4,39^{\mathrm{b}}$ & $5,52^{\mathrm{a}}$ & $4,37^{\mathrm{b}}$ & 19,47 & 0,064 & 0,009 & 0,487 \\
\hline $\begin{array}{l}\text { Gordura } \\
\text { perirrenal }\end{array}$ & 1,99 & 2,13 & $1,79^{\mathrm{b}}$ & $2,51^{\mathrm{a}}$ & $1,87^{\mathrm{b}}$ & 24,43 & 0,446 & 0,004 & 0,825 \\
\hline $\begin{array}{l}\text { Gordura } \\
\text { mesentérica }\end{array}$ & $4,01^{\mathrm{b}}$ & $4,64^{\mathrm{a}}$ & $4,17^{\mathrm{b}}$ & $5,18^{\mathrm{a}}$ & $3,65^{\mathrm{b}}$ & 17,49 & 0,028 & 0,003 & 0,200 \\
\hline
\end{tabular}

Médias, na mesma linha, dentro do nível de concentrado ou grupo genético, seguidas por letras diferentes, diferem entre si $(\mathrm{P}<0,10)$ pelo teste de Tukey.

Paulino et al. (2009), ao trabalharem com animais Nelore de diferentes classes sexuais (machos inteiros, machos castrado e fêmeas), observaram que o tecido adiposo intermuscular foi o local em que foi depositado $46,3 \%$ da gordura total, seguido pelo subcutâneo $(27,0 \%)$, pelo mesentérico $(18,3 \%)$ e, com menor contribuição, o depósito perirrenal $(7,58 \%)$.

O nível de oferta de concentrado não influenciou as características do peso de corpo vazio $(\mathrm{P}>0,10)$. No entanto, o grupo genético teve efeito significativo $(\mathrm{P}<0,10)$ sobre essas características (Tabela 7). As novilhas Angus apresentaram maior PCVZ final do que as NE e NS. Duas situações podem ter provocado esse comportamento, a saber: o maior PCVZ inicial desses animais ou a maior taxa de crescimento $(1,426 \mathrm{~kg} / \mathrm{dia}$ para Angus, 1,041 kg/dia para Nelore e $1,022 \mathrm{~kg} /$ dia para Simental).

Segundo o NRC (2000), espera-se que animais, oriundos de cruzamentos com raças continentais, quando comparados a bovinos obtidos de cruzamentos com raças britânicas e zebuínas, sejam maiores e mais pesados, tenham idade à maturidade mais tardia e carcaça mais magra à mesma idade. No entanto, como mencionado anteriormente, as fêmeas Angus apresentaram consumo de energia metabolizável $(24,13 ; 17,85$ e $18,68 \mathrm{Mcal}$ de EM/dia, para Angus, Nelore e Simental, respectivamente) mais elevado, o que ajuda explicar o maior PCVZ final das novilhas Angus em relação aos demais grupos genéticos. 
Rev. Bras. Saúde Prod. Anim., Salvador, v.13, n.2, p.344-359 abr./jun., 2012 http://www.rbspa.ufba.br ISSN 15199940

Tabela 7. Características, composição química, taxa de deposição e eficiência de deposição dos constituintes químicos do peso de corpo vazio (PCVZ) de fêmeas Nelore, $F_{1}$ Nelore x Angus e $F_{1}$ Nelore x Simental, alimentadas com dois níveis de concentrado (30 e 50\%)

\begin{tabular}{|c|c|c|c|c|c|c|c|c|c|}
\hline \multirow[b]{2}{*}{ Variáveis } & \multicolumn{2}{|c|}{$\begin{array}{c}\text { Nível de } \\
\text { concentrado (NC) }\end{array}$} & \multicolumn{3}{|c|}{$\begin{array}{c}\text { Grupo genético } \\
\text { (GG) }\end{array}$} & \multirow[b]{2}{*}{$\begin{array}{l}\mathrm{CV} \\
(\%)\end{array}$} & \multicolumn{3}{|c|}{ Valor P } \\
\hline & $30 \%$ & $50 \%$ & Nelore & $\begin{array}{c}\text { Nelore } \\
\text { x } \\
\text { Angus }\end{array}$ & $\begin{array}{c}\text { Nelore } \\
\mathrm{x} \\
\text { Simental }\end{array}$ & & $\mathrm{NC}$ & GG & $\begin{array}{c}\mathrm{NC} \\
\mathrm{x} \\
\mathrm{GG} \\
\end{array}$ \\
\hline \multicolumn{10}{|c|}{ Características do peso de corpo vazio } \\
\hline PCVZ inicial & 243,32 & 248,77 & $234,54^{b}$ & $263,35^{\mathrm{a}}$ & $240,24^{b}$ & 9,45 & 0,51 & 0,02 & 0,84 \\
\hline PCVZ final & $340,23^{\mathrm{b}}$ & $361,63^{\mathrm{a}}$ & $323,79^{b}$ & $400,49^{\mathrm{a}}$ & $328,5^{\mathrm{b}}$ & 9,78 & 0,09 & $<, 001$ & 0,44 \\
\hline $\begin{array}{l}\text { Órgãos+Vísceras } \\
\text { (\%PCVZ) }\end{array}$ & 17,04 & 17,40 & $16,79^{\mathrm{b}}$ & $18,12^{\mathrm{a}}$ & $16,74^{\mathrm{b}}$ & 8,02 & 0,47 & 0,04 & 0,99 \\
\hline $\begin{array}{l}\text { Músculo+ } \\
\text { Gordura }(\% \mathrm{PCVZ})\end{array}$ & 53,51 & 53,72 & 53,71 & 53,48 & 53,66 & 3,50 & 0,75 & 0,95 & 0,49 \\
\hline Osso (\% PCVZ) & 11,8 & 10,99 & 11,4 & 10,82 & 11,96 & 12,2 & 0,11 & 0,18 & 0,24 \\
\hline \multicolumn{10}{|c|}{ Composição química do peso de corpo vazio (\%) } \\
\hline Proteína & 16,12 & 16,19 & 15,88 & 15,99 & 16,58 & 7,35 & 0,87 & 0,38 & 0,93 \\
\hline Extrato etéreo & 21,95 & 23,32 & 23,61 & 23,07 & 21,23 & 11,12 & 0,14 & 0,11 & 0,38 \\
\hline Cinzas & $4,19^{\mathrm{a}}$ & $3,65^{\mathrm{b}}$ & 4,01 & 3,75 & 4,01 & 14,46 & 0,01 & 0,45 & 0,92 \\
\hline Água & 57,74 & 56,84 & 56,50 & 57,19 & 58,18 & 3,99 & 0,27 & 0,27 & 0,36 \\
\hline \multicolumn{10}{|c|}{ Composição química do ganho de peso de corpo vazio (\%) } \\
\hline Proteína & 15,74 & 15,87 & 15,41 & 15,59 & 16,4 & 27,11 & 0,93 & 0,86 & 0,89 \\
\hline Extrato etéreo & 44,69 & 46,62 & 47,16 & 43,34 & 46,47 & 22,46 & 0,60 & 0,64 & 0,78 \\
\hline Cinzas & 2,80 & 1,86 & 2,75 & 1,79 & 2,47 & 67,89 & 0,12 & 0,38 & 0,41 \\
\hline Água & 36,77 & 36,44 & 34,92 & 39,64 & 35,26 & 23,23 & 0,91 & 0,35 & 0,76 \\
\hline
\end{tabular}

\begin{tabular}{lccccccccc}
\hline \multicolumn{7}{c}{ Taxa de deposição dos constituintes químicos do peso de corpo vazio (g/dia) } \\
\hline Proteína & 135,82 & 159,57 & $122,05^{\mathrm{b}}$ & $190,21^{\mathrm{a}}$ & $130,82^{\mathrm{b}}$ & 32,76 & 0,18 & 0,005 & 0,82 \\
Extrato etéreo & $377,76^{\mathrm{b}}$ & $468,08^{\mathrm{a}}$ & $371,15^{\mathrm{b}}$ & $526,99^{\mathrm{a}}$ & $370,63^{\mathrm{b}}$ & 25,30 & 0,03 & 0,002 & 0,26 \\
Matéria mineral & 22,64 & 17,56 & 21,48 & 20,92 & 17,9 & 62,61 & 0,30 & 0,82 & 0,24 \\
Água & 328,97 & 370,11 & $283,8^{\mathrm{b}}$ & $491,23^{\mathrm{a}}$ & $273,58^{\mathrm{b}}$ & 31,86 & 0,31 & 0,001 & 0,85 \\
\hline
\end{tabular}

Eficiência de deposição dos constituintes químicos do PCVZ, kg de constituinte depositado/Mcal de EM ${ }^{1}$ consumida

\begin{tabular}{lccccccccc}
\hline $\begin{array}{l}\text { Constituintes } \\
\text { químicos totais }\end{array}$ & 5,06 & 5,19 & $4,98^{\mathrm{b}}$ & $5,68^{\mathrm{a}}$ & $4,72^{\mathrm{b}}$ & 8,88 & 0,43 & 0,001 & 0,76 \\
Proteína & 0,83 & 0,97 & $0,74^{\mathrm{b}}$ & $1,15^{\mathrm{a}}$ & $0,79^{\mathrm{b}}$ & 32,81 & 0,19 & 0,005 & 0,82 \\
Extrato etéreo & $2,29^{\mathrm{b}}$ & $2,84^{\mathrm{a}}$ & $2,25^{\mathrm{b}}$ & $3,2^{\mathrm{a}}$ & $2,25^{\mathrm{b}}$ & 25,31 & 0,03 & 0,002 & 0,26 \\
\hline
\end{tabular}

Energia metabolizável; ${ }^{2}$ Proteína, extrato etéreo, cinzas e água. Médias, na mesma linha, dentro do nível de concentrado ou grupo genético, seguidas por letras diferentes, diferem entre si $(P<0,10)$ pelo teste de Tukey. 
Goulart et al. (2008), ao trabalharem com machos castrados desde 0 nascimento, de quatro grupos genéticos, encontraram superioridade dos animais Nelore x Angus, tanto no peso final de abate, quanto na taxa de crescimento. Esses autores relataram que os pesos finais de abate foram de 508; 453; $450 \mathrm{e}$ $476 \mathrm{~kg}$, respectivamente, para Nelore $\mathrm{x}$ Angus, Nelore x Canchim, Nelore e Nelore $\mathrm{x}$ Simental, e que os ganhos médios diários, nessa mesma sequência, foram de 1,70; 1,50; 1,53 e 1,56kg/dia.

A participação dos órgãos mais vísceras no peso de corpo vazio foi maior para os animais Angus $(\mathrm{P}<0,10)$, o que junto com a gordura interna (perirrenal mais mesentérica) explica o menor rendimento de carcaça desses animais (56,45\% para Angus; 57,78\% para Nelore e 58,18\% para Simental).

Órgãos e vísceras têm elevadas taxas metabólicas, principalmente $\mathrm{o}$ fígado e trato gastrointestinal, o que afeta diretamente a ingestão de matéria seca e a utilização dos nutrientes (FERRELL \& JENKINS, 1998). De acordo com estes autores, diferenças no peso desses órgãos refletem diretamente na condição nutricional dos animais e, consequentemente, no seu desempenho. Esses mesmos autores, ao estudarem novilhos zebuínos (Boran, Brahman e Tuli) e taurinos (Angus e Hereford), relataram haver relação linear positiva entre o peso dos órgãos e a ingestão de matéria seca.. Enquanto Menezes et al. (2007) observaram que, novilhos com maior proporção de sangue zebuíno apresentaram menor capacidade do trato digestório. Dessa forma, as diferenças encontradas nos percentuais de órgãos mais vísceras entre os grupos genéticos, ajudam a explicar o comportamento do PCVZ final.

Animais dos cruzamentos com raças britânicas apresentam maior precocidade na deposição de gordura em comparação com àquelas de raças zebuínas e continentais. Por outro lado, animais oriundos de cruzamentos com raças continentais, por apresentarem maturidade mais tardia, são menos precoce na deposição de gordura e apresentam carcaças mais magras (SUGUISAWA et al., 2006). Dessa forma, esperava-se que as novilhas Angus, por serem mais precoces e de menor tamanho, apresentassem mais extrato etéreo e menos proteína no corpo vazio e no ganho de corpo vazio em comparação à Simental (menos precoce e de maior porte). No entanto, os constituintes químicos do peso de corpo vazio e do ganho de peso de corpo vazio não sofreram efeito dos grupos genéticos $(\mathrm{P}>0,10)$.

Goulart et al. (2008), ao avaliarem bovinos castrados de quatro grupos genéticos (Nelore (NE), Nelore x Angus (NA), Nelore x Canchim (NC) e Nelore $x$ Simental (NS), encontraram resultados diferentes quanto à composição química do corpo vazio. Esses autores encontraram maior percentual de extrato etéreo nos animais NA e NS $(22,60 \%$ para NA e $22,29 \%$ para NS), valores intermediários nos $\mathrm{NC}(20,55 \%) \quad \mathrm{e}$ NE $(20,40 \%)$. No que diz respeito aos percentuais de proteína, esses mesmos autores encontraram maior percentual para os animais NS $(17,80 \%)$, valores intermediários nos $\mathrm{NC}(17,10 \%)$ e $\mathrm{NE}$ $(17,13 \%)$ e menor valor para os NA $(16,55 \%)$ apresentaram maiores valores $(17,80 \%)$,

Com exceção dos teores de cinzas no peso de corpo vazio, o nível de oferta de concentrado não alterou a composição corporal das novilhas $(\mathrm{P}>0,10)$. Houve diferença significativa $(\mathrm{P}<0,10)$ entre os grupos genéticos, quanto às taxas de deposição dos constituintes químicos corporais (Tabela 7). As novilhas NA foram as que apresentaram maiores taxas de deposição dos constituintes 
Rev. Bras. Saúde Prod. Anim., Salvador, v.13, n.2, p.344-359 abr./jun., 2012 http://www.rbspa.ufba.br ISSN 15199940

químicos, resultado reflexo da maior eficiência de utilização da energia metabolizável consumida das Angus (Tabela 7). Além disso, o maior peso de corpo vazio final e taxa de ganho mais elevada desse grupo colaborou para esse comportamento.

Ferrel \& Jenkins (1998), ao pesquisarem sobre novilhos zebuínos (Boran, Brahman e Tuli) e taurinos (Angus e Hereford), só encontraram diferenças na taxa de deposição de gordura, nas quais os animais taurinos apresentaram os maiores valores. Bulle et al. (2002), em pesquisa com tourinhos $1 / 4$ Bos taurus indicus $+3 / 4$ Bos taurus taurus de raça paterna britânica (Shorthorn) e continental (Guelbvieh), encontraram maior deposição de gordura nos animais de raça paterna britânica. No entanto, Berndt et al. (2003), ao avaliarem tourinhos de quatro grupo genético (Nelore, Nelore $\mathrm{x}$ Angus, Nelore $\mathrm{x}$ Canchim e Nelore $\mathrm{x}$ Simental), não encontraram diferenças nas taxas de deposição dos constituintes químicos.

As diferenças encontradas na taxa de deposição dos constituintes químicos observadas nesse estudo com os encontrados na literatura estão coerentes, uma vez que, além do grupo genético, o tipo de manejo, o sistema alimentar e a interação entre essas variáveis têm efeito direto sobre a composição corporal dos animais (GOULART et al., 2008; LOPES et al., 2008).

Assim, constatou-se que o cruzamento entre fêmeas Nelore com animais Angus, bem como o nível de concentrado melhoram o padrão de deposição dos tecidos corporais.

\section{REFERÊNCIAS}

BALDWIN, R.L. Modeling ruminant digestion and metabolism. London: Chapman and Hall, 1995. 592p.

BERNDT, A.; CRUZ, G.M.; ALLEONI, G.F. ALLENCAR, M.M.; LANNA, D.P.D. Tissue deposition rates and empty body composition of purebred and crossbred Nelore bulls.

Journal of Animal Science, v.81, p.306, 2003. Suppl1.

BIANCHINI, W.; SILVEIRA, A.C.; ARRIGONI, M.B.; JORGE, A.M.; MARTINS, C.L.; RODRIGUES, E. Crescimento e características de carcaça de bovinos superprecoces Nelore, Simental e mestiços. Revista Brasileira de Saúde e Produção Animal [Online], v.9, n.3, p.554-564, 2008.

BULLE, M.L.M.; RIBEIRO, F.G.; LEME, P.R.; TITTO, E.A.L.;LANNA, D.P.D. Exigência líquidas de energia e proteína de tourinhos de dois grupos genéticos alimentados com dietas de alto teor de concentrado. Revista Brasileira de Zootecnia, v.31, n.1, p.436-443, 2002. Suppl2.

CAMARGO, A.M.; RODRIGUES, V.C.; SOUSA, J.C.D.; MORENZ, M.J.F.; SILVA, J.C.G.; CABRAL NETO, O.; RAMALHO, R.O.S.; RAMOS, K.C.B.T. Características da carcaça de novilhas $1 / 2$ Guzerá x $1 / 4$ Simbrasil x $1 / 4$ Nelore, terminadas em confinamento e abatidas com diferentes pesos. Boletim de Indústria Animal, v.65, n.3, p.175182, 2008. 
Rev. Bras. Saúde Prod. Anim., Salvador, v.13, n.2, p.344-359 abr./jun., 2012 http://www.rbspa.ufba.br ISSN 15199940

EUCLIDES FILHO, K.; EUCLIDES, V.P.B.; FIGUEIREDO, G.R.; BARBOSA, R.A. Eficiência bionutricional de animais Nelore e seus mestiços com Simental e Aberdeen Angus em duas dietas. Revista Brasileira de Zootecnia, v.30, n.1, p.77-82, 2001.

EUCLIDES FILHO, K.; FIGUEIREDO, G.R.; EUCLIDES, V.P.B. SILVA, L.O.C.; ROCCO, V.; BARBOSA, R.A.; JUNQUEIRA, C.E. Desempenho de diferentes grupos genéticos de bovinos de corte em confinamento. Revista

Brasileira de Zootecnia, v.32, n.5, p.1114-1122, 2003.

FERNANDES, H.J.; PAULINO, M.F.; MARTINS, R.G.R.; VALADARES FILHO, S.C.; TORRES, R.A.; PAIVA, L.M.; SILVA, A.T.S. Composição corporal de garrotes inteiros de três grupos genéticos nas fases de recria e terminação. Revista Brasileira de Zootecnia, v.33, n.6, p.1581-1590, 2004.

FERRELL, C.L.; JENKINS, T.G. Body composition and energy utilization by steers of diverse genotypes fed a highconcentrate diet during the finishing period: II. Angus, Boran, Brahman, Hereford, and Tuli Sires. Journal Dairy Science, v.76, p.647-657, 1998.

GOULART, R.S.; ALENCAR, M.M.; POTT, E.B; CRUZ, G.M.; TULLIO, R.R.; ALLEONI, G.F.; LANNA, D.P.D.Composição corporal e exigências líquidas de proteína e energia de bovinos de quatro grupos genéticos terminados em confinamento. Revista Brasileira de Zootecnia, v.37, n.5, p.926-935, 2008.

HALL, M.B. Calculation of nonstructural carbohydrate content of feeds that contain non-protein nitrogen. Gainesville: University of Florida, 2000. p.A-25 (Bulletin, 339).
LOPES, J.S.; RORATO, P.R.N.; WEBER, T.; RODRIGUES, R.D.; COMIN, J.G.; DORNELLES, M.A.

Metanálise para características de carcaça de bovinos de diferentes grupos genéticos. Ciência Rural, v.38, n.8, p.2278-2284, 2008.

MALHADO, C.H.M.; CARNEIRO, P.L.S.; MARTINS FILHO, R.; PEREIRA, D.G.; AFFONSO, P. R.A.M.; AZEVEDO, D.M.M.R.; SOUZA, J.C. Parâmetros e tendência genética da taxa de maturação e peso assintótico de bovinos da raça Nelore no estado da Bahia. Revista Brasileira de Saúde e Produção Animal [Online], v.10, n.2, p.245-255, 2009.

\section{MARCONDES, M.I.; VALADARES} FILHO, S.C.; PAULINO, P.V.R.; VALADARES, R.F.D.; PAULINO, M.F.; NASCIMENTO, F.B.; FONSECA, M.A. Exigências nutricionais de proteína, energia e macrominerais de bovinos Nelore de três classes sexuais. Revista Brasileira de Zootecnia, v.38, n.8, p.1587-1596, 2009.

MENEZES, L.F.G.; RESTLE, J.; BRONDANI, I.L.; KUSS, F.; ALVES FILHO, D.C.; SILVEIRA, M.F.; LEITE, D.T. Órgãos internos e trato gastrintestinal de novilhos de gerações avançadas de cruzamento rotativo entre as raças Charolês e Nelore terminados em confinamento. Revista Brasileira de Zootecnia, v.36, n.1, p.120-129, 2007

MORALES, D.C.; CHARDULO, L. A. L.; SILVEIRA.A.C.; OLIVEIRA, H.N., ARRIGONI, M.B.; MARTINS, C.L.; CERVIERI, R.C. Características de qualidade de carne de bovinos de corte de diferentes tamanhos à maturidade submetidos ao sistema superprecoce. Acta Scientiarum, v.24, n.4, p.1-2, 2002. 
Rev. Bras. Saúde Prod. Anim., Salvador, v.13, n.2, p.344-359 abr./jun., 2012 http://www.rbspa.ufba.br ISSN 15199940

NATIONAL RESEARCH COUNCIL NRC. Nutrient requeriments of beef cattle. 7.ed. Washington: National Academic Press, 2000. 242p.

PAULINO, P.V.R.; VALADARES FILHO, S.C.; DETMANN, E.; VALADARES, R.F.D.; FONSECA, M.A.; MARCONDES, M.I. Deposição de tecidos e componentes químicos corporais em bovinos Nelore de diferentes classes sexuais. Revista Brasileira de Zootecnia, v.38, n.12, p.2516-2524, 2009.

PEROTTO, D.; CUBAS, A.C.; ABRAHÃO, J.J.; MELLA, S.C. Ganho de peso da desmama aos 12 meses e peso aos 12 meses de bovinos Nelore e cruzas com Nelore. Revista Brasileira de Zootecnia, v.30, n.3, p.730-735, 2001a.

PEROTTO, D.; ABRAHÃO, J.J.S.; KROETZ, I.A. Produtividade à desmama de novilhas Nelore e $\mathrm{F}_{1}$ Bos taurus x Nelore e Bos indicus $\mathrm{x}$ Nelore. Revista Brasileira de Zootecnia, v.30, n.6, p.1712-1719, 2001b.

ROCHA JÚNIOR, V.R.; SILVA, F.V.; BARROS, R.C.; REIS, S.T.; COSTA, M.D.; SOUZA, A.S.; CALDEIRA, L.A.; OLIVEIRA, T.S.; OLIVEIRA, L.L.S. Desempenho e características de carcaça de bovinos Nelore e Mestiços terminados em confinamento. Revista Brasileira de Saúde e Produção Animal [Online], v.11, n.3, p.865-875, 2010.
SAINZ, R.D.; HASTING, E. Simulation of the development of adipose tissue in beef cattle. In: McNAMARA, J.P.; FRANCE, J.; BEEVER, D.E. (Eds.). Modelling nutrient utilization in farm animals. New York: CAB International, 2000. p.175-182.

\section{SAS INSTITUTE. SAS/STAT software. Cary, 2000.}

SILVA, D.J.; QUEIROZ, A.C. Análise de Alimentos: métodos químicos e biológicos. 3. ed. Viçosa: Universidade Federal de Viçosa, 2002, 235p.

SUGUISAWA, L.; MATTOS, W.R.S.; OLIVEIRA, H.N. SILVEIRA, A.C.; ARRIGONI, M.B.; SOUZA, A.A. Correlações simples entre as medidas de ultra-som e a composição da carcaça de bovinos jovens. Revista Brasileira de Zootecnia, v.35, n.1, p.169-176, 2006.

VAZ, F.N.; RESTLE, J. Ganho de peso antes e após os sete meses no desenvolvimento e nas características de carcaça e carne de novilhos Charoles abatidos aos dois anos. Revista

Brasileira de Zootecnia, v.32, n.3, p.699-708, 2003.

WEISS, W.P. Energy prediction equations for ruminant feeds. Cornell: Nutrition conference for feed manufactures, 1999. p.176-185.

Data de recebimento: 18/08/2011

Data de aprovação: 27/04/2012 